\title{
Erratum: Big data analytics adoption: A case study in a large South African telecommunications organisation
}

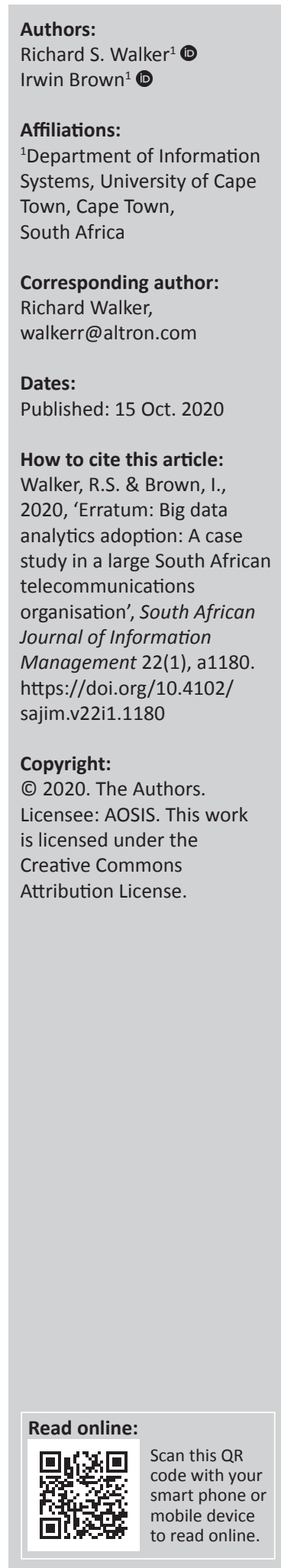

In the version of this article initially published, Walker, R.S. \& Brown, I., 2019, 'Big data analytics adoption: A case study in a large South African telecommunications organisation', South African Journal of Information Management 21(1), a1079. https://doi.org/10.4102/sajim.v21i1.1079, the corresponding author's email address was given incorrectly. The correct email address should be walkerr@altron.com instead of uriz@ariel.ac.il.

This correction does not alter the study's findings of significance or overall interpretation of the study's results. The publisher apologises for any inconvenience caused. 


\section{Big data analytics adoption: A case study in a large South African telecommunications organisation}

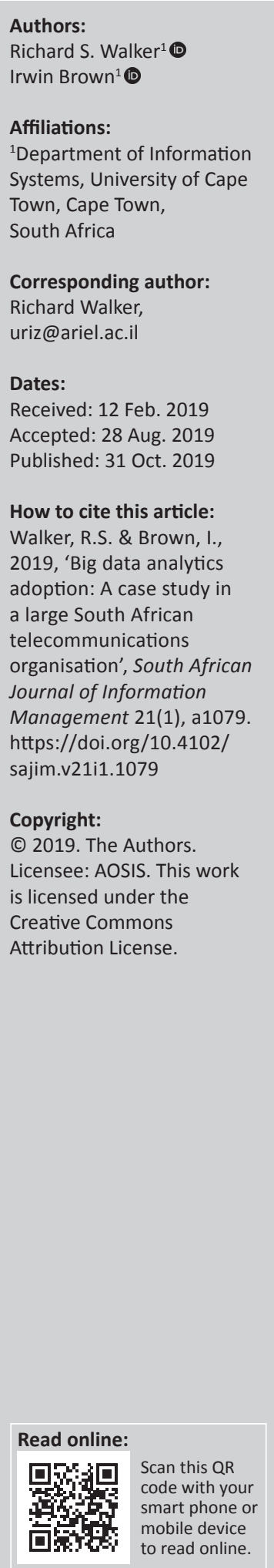

Background: Big data analytics (BDA) offers a frontier of opportunities across all industries enabling improvements in marketing, customer service and product development. The adoption process for BDA is often challenging for organisations, given the complexities associated with it.

Objective: The objective of this study was hence to understand factors that influence the BDA adoption process in organisations. The technology-organisation-environment framework was combined with factors from a Big Data Adoption model and used as a foundation for the study.

Method: A case study research strategy was performed on a large telecommunication organisation. Themes were identified which provided rich explanations into the factors influencing the BDA adoption process in organisations.

Results: Five technological factors were confirmed to influence the BDA adoption process. These were: (1) relative advantage, (2) complexity, (3) compatibility, (4) trialability and (5) data quality. Four organisational factors were confirmed to influence the BDA adoption process. These were: (1) top management support, (2) human resource expertise, (3) business and information technology (IT) alignment and (4) organisation size. Five environmental factors were confirmed to influence the BDA adoption process. These were: (1) competitive pressure, (2) data privacy, (3) vendor support, (4) IT fashion and (5) regulatory requirements. Two factors were confirmed as influencing an organisations' ability to move from intention to adopt BDA to actual deployment. These were: (1) complexity tolerance and (2) paradigm shifts.

Conclusion: This study provided evidence that organisations that have a high tolerance for complexity are more likely to move rapidly from intention to adopt BDA to actual deployment and effectively reduce the deployment gap.

Keywords: Big data analytics; adoption process; telecommunications; complexity tolerance; deployment gap.

\section{Introduction}

Big data analytics (BDA) is emerging as a hot topic amongst scholars and practitioners (Wamba et al. 2017) and is considered to be the most important technology disruption since the rise of the Internet (Chen, Preston \& Swink 2015a). To distinguish 'big data' from the traditional structured relational data typically stored by organisations, it has often been described in terms of its three main characteristics, that is, volume - regarding the large amount of data; velocity - which makes reference to the speed of data creation and transfer; and variety - referring to the different types of data collected (Salleh \& Janczewski 2016). Additional characteristics alluded to include veracity, value, variability and visualisation (Mikalef et al. 2018). Big data analytics can be defined holistically as the infrastructure, technologies, tools, methods, techniques and processes used to source, store and analyse big data to produce actionable insights (Lehrer et al. 2018; Mikalef et al. 2018).

Popular innovation theories have been used over time to explain technology adoption, with the technology-organisation-environment (TOE) framework (Tornatzky \& Fleischer 1990), the most commonly uses. Studies in BDA adoption usually focus on the adoption intentions that relate to the initiation stage and very few on the adoption decision stage that leads to deployment (Chen, Kazman \& Matthes 2015b). Although the TOE framework has generally been empirically supported, it is limited in explaining the paradoxical phenomena that despite big data being the most significant technology disruption since the rise of the Internet, big data deployments are still scarce (Chen et al. 2015b). A 'limbo stage' is observed in BDA adoption where organisations 
signal an intention to adopt but remain in an experimental stage for years. This is known as the deployment gap (Chen et al. 2015b). This study aims to explain the factors influencing the adoption process of BDA in organisations by combining the TOE framework with factors from the Big Data Adoption model of Chen et al. (2015b) to provide insights into the deployment gap.

In the next section, the conceptual background is presented leading to the development of the conceptual framework used as the basis for the study. Thereafter the research methodology is described before the results are presented and discussed, and conclusions are drawn.

\section{Conceptual background Big data analytics in the telecommunications sector}

Difficulties in measuring success of BDA initiatives suggest that there is no 'one size fits all' solution and the potential value varies significantly between the varieties of sectors globally (Jokonya 2015). This study was conducted in the telecommunications sector, and hence some context to this industry and the relevance of BDA is provided here. The telecommunications sector of specific interest is the sector that provides fixed wire and/or wireless (including mobile) voice and/or data services to consumers. The unique advantage of mobile network operators is that they are in constant contact with their customers via their mobile devices (Jokonya 2015). Mobile technology usage behaviour has changed significantly with the introduction of smartphones which generate 14 times more data volumes than a basic mobile phone (Verma \& Verma 2014). The demand for high bandwidth requires significant investment in network infrastructure. Content and application providers such as Google and Facebook get profit without contributing to the infrastructure investment. Telecommunication operators need to produce new innovative services to generate revenues (Czarnecki \& Dietze 2017).

Analysts and research companies forecast marginal revenue growth in the telecommunications sector for the foreseeable future. From a global perspective, the telecommunication industry is regarded as a stagnating market (Czarnecki \& Dietze 2017). Telecommunication operators are therefore confronted with two contrary conditions where stagnating and innovating markets are mixed (Czarnecki \& Dietze 2017). In such an environment, insights provided through BDA may provide the means to manage under these conditions, but challenges with BDA adoption present a hindrance (Malaka \& Brown 2015).

\section{Theoretical development}

The theoretical development is largely based on the traditional TOE framework, whereby technological, organisational and environmental factors relevant to BDA adoption are identified in the literature. In addition, factors related to the deployment gap are also included, drawing from the work of Chen et al. (2015b).

\section{Process of adoption}

Innovation adoption in organisations can be divided into three phases of initiation or intention to adopt, adoption decision and implementation or deployment (Chen et al. 2015b; Rogers 2010). Most organisational technology adoption studies focus only on the intention to adopt stage and few on the adoption decision stage that leads to deployment (Chen et al. 2015b).

\section{Moderating factors}

Chen et al. (2015b) suggest complexity tolerance and paradigm shifts as key to understand the deployment gap observed in many BDA adoption processes. In effect, these factors can be conceptualised as moderating the relationship between intentions to adopt actual deployment.

Complexity tolerance: Complexity tolerance is defined as 'the extent to which an enterprise can tolerate the complexity in the technology and in its implementation process' (Chen et al. 2015b). Unlike traditional information technology (IT) artefacts such as enterprise resource planning (ERP) and service-oriented architecture (SOA), BDA can be thought of as a 'hammer looking for nails' (Chen et al. 2015b). This increases the level of uncertainty and ambiguity involved in BDA adoption decisions (Chen et al. 2015b). An intolerance of ambiguity implies a need to avoid misunderstood or undefined stimuli (Iederan, Curseu \& Vermeulen 2009). Chen et al. (2015b) argue that if the value realised by adopting BDA can be clearly understood, then the decision-making process becomes more rational. This, however, is not often the case with BDA adoption where value is not easily predicted or quantifiable. The proposition suggested is:

P1: The organisation's complexity tolerance influences its ability to move from BDA intention to adopt actual deployment.

Paradigm shift: Paradigm shifts are required when there is a fundamental change in the basic practises and assumptions in a discipline (Chen et al. 2015b). Big data analytics is described as disrupting the traditional information value chain in the information systems domain (Abbasi, Sarker \& Chiang 2016). Organisations need to embrace a data analytics culture to ensure that the employees understand the essential concepts and embrace analytical thinking (Mneney \& Van Belle 2016). The ability to absorb a paradigm shift may influence an organisation's ability to move from intention to adopt actual deployment of BDA. Paradigm shifts also increase the complexity of BDA adoption and thus reduce complexity tolerance (Chen et al. 2015b).

Thus, the two propositions suggested are as follows:

P2: The ability to absorb paradigm shifts influences the organisation's ability to move from BDA intention to adopt actual deployment.

P3: The extent of the paradigm shift influences an organisation's complexity tolerance for BDA.

\section{Technological factors}

Relative advantage: Relative advantage has been demonstrated in many studies as a major influence on 
technology adoption. It recognises the advantages of adopting a new technology by comparing its benefits relative to an existing technology (Chen et al. 2015b). It is understood that BDA can provide many benefits to an organisation which include data sourcing, facilitating data sharing, effective decision-making support and improved customer service (Ahmad, Ahmad \& Hashim 2016; Lehrer et al. 2018). More specific benefits for telecommunications include fraud detection, network optimisation and retention of service data (Ahmad et al. 2016). The proposition supported is:

\section{P4: Relative advantage influences the BDA adoption process}

Complexity: Complexity is defined as the degree to which a technology is perceived as being challenging to implement and use (Rogers 2010). The lower the perceived complexity of BDA, the more likely it will be successfully deployed (Ahmad et al. 2016). To address the technical challenges stemming from big data and its characteristics, an array of technologies have rapidly evolved, for example, data lakes, stream analytics, mobile analytics and so on (Lehrer et al. 2018). This has added a level of complexity to the deployment of BDA systems and complicated the adoption decision-making process. Adoption requires selecting many technology components to enable the BDA system (Chen et al. 2015b). The proposition supported is as follows:

P5: Complexity influences the BDA adoption process.

Compatibility: Compatibility refers to the degree to which a new technology fits with existing needs, practices, past experiences and values of an organisation (Nedev 2014). Compatibility has been a frequently cited factor affecting adoption of new technologies (Chen et al. 2015a, 2015b). Organisational capabilities are shaped by their history and past experiences which reflect their values and work practices (Chen et al. 2015a). Innovations that do not align to existing organisational values and standards are unlikely to be adopted or the adoption rate will be slow. Conversely, the higher the perceived compatibility of BDA, the faster the adoption rate (Ahmad et al. 2016; Hung et al. 2016; Nedev 2014; Salleh \& Janczewski 2016). The proposition supported is as follows:

P6: Compatibility influences the BDA adoption process.

Trialability: Potential adopters that are allowed to experiment with a new innovation are more likely to adopt (Rogers 2010). Having the ability to test and assess the innovation prior to adoption will increase the rate of adoption (Sun et al. 2018). Trialability of innovations reduces uncertainty around adoption, as organisations can learn by doing (Ahmad et al. 2016). Thus, the proposition supported is as follows:

P7: Trialability influences the BDA adoption process.

Data quality: Big data analytics involves collecting and integrating data from multiple sources. Decision-making is affected by the quality of the data. The more relevant, timely, reliable and accurate the data, the more it positively affects decision-making (Fredriksson 2015; Malaka \& Brown 2015; Zhu et al. 2016). The proposition supported is as follows:

P8: Data quality influences the BDA adoption process.

\section{Organisational factors}

Top management support: If top management has a positive belief in the potential usefulness of an IT system, then they will ensure that the correct actions are taken to support the adoption of the system (Ahmad et al. 2016; Chen et al. 2015a; Hung et al. 2016; Nedev 2014; Salleh \& Janczewski 2016). By championing and promoting the implementation of the system, top management acts as agents facilitating change in the organisation's culture, norms and values (Chen et al. 2015a):

P9: Top management support influences the BDA adoption process.

Human resource expertise: BDA adoption requires a high level of IT sophistication. Information technology sophistication not only implies technical capabilities but also IT human resources within the organisation which should include technological knowledge and expertise (Chwelos, Benbasat \& Dexter 2001). It is suggested that the availability of professionals with the correct IT skills and capabilities to perform business analytics is crucial in the context of BDA usage (Chen et al. 2015a). In a study on BDA implementation failures, it was identified that the most prominent challenge was lack of skills (Fredriksson 2015).

The proposition supported is as follows:

P10: Human resource expertise influences the BDA adoption process.

Business and information technology alignment: The alignment between business and information technology has been a persistent concern in Information technology management (Kappelman, McLean, Johnson \& Gerhart 2014). In the BDA context, it is posited as a factor influencing adoption (Chen et al. 2015b) and hence the proposition:

P11: Business and IT alignment influences the BDA adoption process.

Organisation size: Organisation size can affect the success of BDA adoption as BDA comes at a significant cost and smaller businesses would have a longer payback period (Hung et al. 2016). Larger organisations, however, would need to overcome other factors, such as integration of knowledge from different departments, operational objective adjustments and data amendments (Sun et al. 2018). The proposition supported is as follows:

P12: Organisation size influences the BDA adoption process.

\section{Environment}

Competitive pressure: Competitive pressure refers to the pressure from competitors to stay current and adopt new 
technologies (Nedev 2014). Stakeholders such as customers, suppliers and competitors all contribute to competitive pressure on organisations (Hung et al. 2016). Such competitive pressure causes organisations to consider the adoption of new technologies such as BDA, if competitors are adopting or have adopted it (Oliveira \& Martins 2011). It also follows that competitive pressure raises the tolerance for complexity (Chen et al. 2015b).

The propositions supported are as follows:

P13: Competitive pressure influences the BDA adoption process.

P14: Competitive pressure influences an organisation's complexity tolerance for BDA.

Data privacy concerns: Through its storage capability (Lehrer et al. 2018), BDA enables telecommunication operators to record billions of customer communication behaviours with the object of increasing customer experience for higher profits. For customers, however, the telecommunications data are privacy-sensitive such as payment records, call records, mobile search queries and billing records (Hu et al. 2015). The BDA characteristics such as volume, velocity and variety contribute to the unique threats that magnify the challenges for managing BDA security compared to traditional data environments (Salleh \& Janczewski 2016). The proposition supported is as follows:

P15: Data privacy concerns influence the BDA adoption process.

Vendor support: Lack of commitment or effectiveness from vendors results in slow BDA implementations. Reliance on consultants may lead to loss of control over a project, increased costs and time commitment (Fredriksson 2015). The proposition supported is as follows:

P16: Vendor support influences the BDA adoption process.

Information technology fashion: Information technology fashion can be considered as the 'hype' that exists around a technology pedalled by vendors, consultants, the media and so on (Chen et al. 2015b). As such, we classify it as an environmental factor. Chen et al. (2015b) claim that factors such as IT fashion influence an organisation's adoption of BDA, and the ability to tolerate complexity, much like the influence of competitive pressure.

The propositions supported are as follows:

P17: Information technology fashion influences the BDA adoption process.

P18: Information technology fashion influences an organisation's complexity tolerance for BDA.

Regulatory requirements: As the foundation of $\mathrm{BDA}$ is predominantly unstructured data, ensuring compliance with privacy regulatory requirements is far more complex and negatively affects BDA adoption in organisations (Salleh \& Janczewski 2016). Regulatory compliance is of concern for telecommunication operators as they manage sensitive information about customers. The proposition supported is as follows:

P19: Regulatory requirements influence the BDA adoption process.

\section{Research methodology}

Case study research has gained wide acceptance in IT over the past few decades (Klein \& Meyers 1999). It is a useful approach when a phenomenon is complex and an in-depth investigation is needed to understand it in context (Yin 2013). The purpose of this study was to explain the factors influencing the adoption process of BDA in telecommunications using a case study. Conducting explanatory research required the researcher to pay attention to the explanations offered by the case study participants. Cross-questioning participants resolved areas of uncertainty (Babbie 2015). Participants were chosen because of their involvement in the BDA adoption process in the case organisation and experience in business intelligence (BI) and BDA. Table 1 lists the participants who were interviewed for this study including their current role, experience and number of years in the organisation.

In-depth qualitative interviews were conducted by using a semi-structured approach where questions were less formal in nature. A list of questions was compiled to facilitate discussions with the participants. All the interview recordings were transcribed by the researcher. The transcriptions were checked to ensure accuracy. Secondary data collected by the researcher included the organisation's big data platform high-level design, data source ingestion high-level design and BDA business strategy documents. The time frame was cross-sectional as it explored the factors influencing the adoption process of BDA in telecommunications at a point in time (Saunders, Lewis \& Thornhill 2009). Thematic analysis was used to analyse the data collected (Braun \& Clarke 2006). A deductive approach was used where the propositional statements were interrogated in the empirical situation.

\section{Data analysis Case background}

The organisation chosen for this study is a large mobile telecommunications organisation in South Africa. The organisation has a footprint in a number of countries in Africa. The organisation has matured in business intelligence (BI) reporting over the years as a pre-cursor to BDA, and has

TABLE 1: List of participants.

\begin{tabular}{llc}
\hline Code & Participants' role & Years in the organisation \\
\hline EA & Senior executive & 20 years \\
EB & Executive & 13 years \\
EC & Executive & 18 years \\
MA & Manager & 18 years \\
MB & Manager & 15 years \\
SA & Senior specialist & 10 years \\
SB & Senior specialist & 10 years \\
SC & Senior specialist & 10 years \\
SD & Senior specialist & 10 years \\
\hline
\end{tabular}


extensive experience in customer value management and network planning.

\section{Factors influencing the big data analytics adoption decision process}

Each of the propositions were interrogated which yielded a rich understanding of how the factors played a role on BDA adoption processes in organisations. Each will be discussed in turn. Participants will be referred to using the codes in Table 1.

\section{Moderating factors}

Complexity tolerance: Participant SC (senior specialist, 10 years' experience) explained that the stronger the organisation's tolerance for complexity, the easier it would be to move from intention to actual deployment: ' ... if you have a high tolerance for complexity you would push through those complex boundaries and problems and you can get from intention to adopt to deployment'. When asked about what ambiguities the organisation needed to tolerate during the BDA adoption process, the participants explained that the organisation had very clear objectives for BDA and did not think that there was any ambiguity in what needed to be performed. It was also observed that the organisation does have specific use cases and a roadmap defining future delivery plans:

'I think ambiguity is where we didn't have a problem. We have a very specific outcome we are driving so we know what our problem is ...' (EA, senior executive, 20 years' experience)

The proposition P1 is therefore supported: The organisation's complexity tolerance influences its ability to move from intention to adopt actual deployment.

Paradigm shift: Participant SA explained that there had been a shift to an analytical perspective. The organisation has up until now only been involved in predictive and some prescriptive analytics. It is now moving to more machine learning and artificial intelligence enabling them to predict subscribers' behaviour: 'We really want to move to machine learning and artificial intelligence components where we start predicting subscribers' behaviour'. Participants agreed that the organisation's ability to absorb a paradigm shift affected its ability to move from intention to adopt actual deployment:

'If the paradigm shift is large it will take longer to move between intention to adopt and deployment. If it's small you can go through the stages quickly.' (EB, executive, 13 years' experience)

Thus, there is support for the proposition P2.

Paradigm shifts influence the organisations' complexity tolerance: There were a number of paradigm shifts that needed to be absorbed for the organisation to move from intention to adoption to actual deployment. Participant EB agreed that the extent of the paradigm shift influenced the organisation's ability to tolerate complexity:
'If the paradigm shift was small, the tolerance for complexity would be easier.' (EB, executive, 13 years' experience)

Participant MB explained that once the paradigm shift has been achieved, the tolerance for complexity is greater, inferring that the knowledge barrier has been overcome:

'I think if you have made the shift your tolerance for complexity is higher because you understand it.' (MB, manager, 15 years' experience)

These statements support proposition P3: The extent of the paradigm shift influences an organisation's complexity tolerance.

\section{Technology}

\section{Relative advantage}

Participants contrasted BDA with traditional BI systems that utilise technologies such as data warehouses and BI reporting tools to deliver information for decision-making (Jooste, Van Biljon \& Mentz 2014). Participant MA explained that BDA provides the ability to mine across structured and unstructured data and add real-time triggers for deeper insights. The ability to do this with traditional BI systems is limited:

'... you can get much more deep and personalised insights using a platform like this.' (MA, manager, 18 years' experience)

Although this statement suggests that BDA provides significant benefits over traditional BI systems, most of the participants agreed that it would not replace existing systems. Big data analytics is seen as complementing the existing systems and therefore part of the BI ecosystem. Participant EA explained:

'... there are definite advantages that can complement the ecosystem but it cannot necessarily replace the current technologies.' (EA, senior executive, 20 years' experience)

Although not explicitly stated that the advantages of BDA over traditional BI systems influence the adoption process, it can be inferred. Because of the advantages highlighted by the participants, the proposition P4 is supported.

\section{Complexity}

Participant EA explained that the complexity in BDA lies more in making sense of the data. The data scientists are required to extract insights from the data:

'I think the complexity is more in the use of the technology.' (EA, senior executive, 20 years' experience)

This creates a challenge for adoption, hence providing support for proposition P5: Complexity influences the adoption process.

\section{Compatibility}

Participant SB explained that learnings and experiences gained from adopting other systems in the organisation have 
assisted them in the BDA adoption process. Standards and processes have been reused and applied to big data:

'A lot of the standards that we use have been adopted and reused and possibly improved.' (SB, senior specialist, 10 years' experience)

Participant EA explained that the degree of compatibility depends on the requirements to integrate to other systems:

'Software is always compatible, it just depends how hard you have to work it, joining the things together.' (EA, senior executive, 20 years' experience)

These statements support proposition P6: Compatibility influences the adoption process.

\section{Trialability}

Trialing BDA allows organisations to understand the challenges that could be experienced during implementation. Participant SA explained that the learnings from the trial could prevent them from making similar mistakes in production:

'... it also highlights some of the challenges and you can ensure that you don't fall into those pitfalls.' (SA, senior specialist, 10 years' experience)

This statement provides support for proposition P7: Trialability influences the adoption process.

\section{Data quality}

Participant EA explained that the organisation has learned from experience in the data warehouse that there is a value in assuring and reconciling the ingested data back to where the data were sourced:

'We know how to build these controls, we know how to implement the framework, we can re-apply it across sources.... if you do it up front it becomes part of the day to day running of your system.' (EA, senior executive, 20 years' experience)

Participant SB, however, did not believe that data quality was as important as in the data warehouse and was dependent on the use of the data:

'... if you just want to do demographics and stuff like that then your data quality is not that important.' (SB, senior specialist, 10 years' experience)

Participant MB explained that introducing poor-quality data into the system has long-term negative effects on the perception of the data:

'... if they don't trust the data they won't use the system.' (MB, manager, 15 years' experience)

This confirms proposition P8: Data quality influences the adoption process.

\section{Organisation}

\section{Top management support}

Participant EA explained that the adoption process was an initiative driven by the top management in the organisation and therefore has a positive influence on the adoption process:

'In this case, because it's on the agenda of the CEO, CIO and CTO it's much easier, you get more focus from everybody.' (EA, senior executive, 20 years' experience)

Participant MB explained that top management support ensures that your chances of success are improved because you have support from both the solution owners in the business and the IT division:

'Business are willing to partner with IT, rather than pointing at IT to provide the solution, business is prepared to partner with IT to ensure that both bring the solution.' (MB, manager, 15 years' experience)

Thus, proposition P9 is supported: Top management support influences the adoption process.

\section{Human resource expertise}

Participant EA explained that the organisation has had to adopt a different style of engagement to on-board specialist data engineering resources. Traditionally, an organisation of its size would go for large reputable solution providers to implement a project of this scale. Because of the lack of experience in international vendor's local resources, the executives in the organisation opted to contract in smaller, more specialised organisations to achieve their objectives:

'And it also speaks to adopting different strategies for that, reaching out to small specialised companies, we would typically have gone to big international firms.' (EA, senior executive, 20 years' experience)

Participant EA went on to explain that this has not been seen in a negative light. The smaller organisations are more agile and have been able to achieve results in shorter periods of time:

'... if we had gone to big international firms we would not be where we are today. We would still be negotiating contracts.' (EA, senior executive, 20 years' experience)

Thus, there is support for proposition P10: Human resource expertise influences the adoption process.

\section{Business and information technology alignment}

Data scientists in the BDA context are part of the delivery team even though they report to business. Participant EA explained that this is a shift in the traditional model:

'So the data scientist is aligned closely with the business but I see it completely as a delivery role.' (EA, senior executive, 20 years' experience)

This supports proposition P11: Business and IT alignment influences the adoption process.

\section{Organisation size}

Participant EC suggested that organisational size negatively influences the adoption process of BDA. As stated: 
'I would say the size can be a hindering factor.' (EC, executive, 18 years' experience)

The volume of data and the significant number of sources that need to be ingested mean that the delivery team has to engage with a multitude of departments throughout the organisation to ingest the data. Coordinating between departments introduces the challenges that slow down the adoption process:

'Everything gets more complex when it's bigger. I think the general rule, the larger the organisation, the more complex it is.' (EC, executive, 18 years' experience)

Proposition P12 is therefore supported: Organisation size influences the adoption process.

\section{Environment}

\section{Competitive pressure}

Participant EA explained that competitive pressure influences BDA adoption:

'... if you are seeing other companies being successful with a technology then you would be wanting to embrace it and be more willing to embrace it because you see benefit.' (EA, senior executive, 20 years' experience)

Thus, there is support for proposition P13: Competitive pressure influences the adoption process.

\section{Competitive pressure influences complexity tolerance}

Participants agreed that competitive pressure would positively influence the organisation's ability to tolerate complexity:

'If you have that competitive pressure I think people will have a higher tolerance for that complexity of the project.' (SC, senior specialist, 10 years' experience)

There is support for P14: Competitive pressure influences an organisations' complexity tolerance.

\section{Data privacy}

Participant EB expressed concerns that because of the hype around big data, it would be harder to implement the controls required to ensure that privacy is managed:

'I think adoption this time is going to be more difficult because you need to apply more rules it's going to take you longer to do things initially.' (EB, executive, 13 years' experience)

This meant that the controls would need to be more tightly managed. There was therefore support for proposition P15: Data privacy influences the adoption process.

\section{Vendor support}

Vendor support is considered critical for the BDA adoption process. The vendors are used for the implementation and development of the environment. Selecting the correct vendor was considered essential. Participant MB claimed that it was important that the vendor already had experience and was able to drive the BDA adoption:

'Using the right vendor is very critical. They should have already had experience putting down a BDA and driving adoption with the business as well.' (MB, manager, 15 years' experience)

Participant MA, however, explained that you need someone whom you can trust and it would be hard to find an organisation that had implemented a project of this scale:

'... you need to find someone you can trust but there are probably not very many companies who have implemented big data platforms on such a large scale.' (MA, manager, 18 years' experience)

Thus, there is support for proposition P16: Vendor support influences the adoption process.

\section{Information technology fashion}

Participant EA explained that because of the hype around BDA, there are unrealistic expectations which lead to pressure being placed on the BDA implementation team to deliver results:

'It makes it harder because you have this misunderstood concept, you have a lot of expectation hype, a lot of time pressure which makes you compromise various decisions.' (EA, senior executive, 20 years' experience)

There is therefore support for proposition P17: IT fashion influences the adoption process.

\section{Information technology fashion influences an organisation's complexity tolerance}

Participant SB explained that people who get caught up in the hype underestimate the complexity and push on with adoption regardless of the complexity:

'People hear these terms and potentially what it can bring but they don't understand the complexity of what it can bring.' (SB, senior specialist, 10 years' experience)

Proposition P18 is supported: IT fashion influences an organisations' complexity tolerance.

\section{Regulatory requirements}

Participant MA agreed that the data stored in the big data platform would need to be used in an ethical and responsible manner and comply with the regulatory requirements:

'From our organisation's perspective we would have to make sure we use the information in an ethical and responsible manner.' (MA, manager, 18 years' experience)

Participant EA claimed that compliance with regulatory requirements is an important factor for the organisation:

'We are very serious about it. If we don't take it seriously from the beginning, we could end up being exposed and then having to run around and fix it.' (EA, senior executive, 20 years' experience)

There is therefore support for proposition P19: Regulatory requirements influence the BDA adoption process. 


\section{Ethical consideration}

Ethical clearance was obtained from the Faculty of Commerce Ethics in Research Committee, University of Cape Town in 2017.

\section{Discussion}

In this study, the TOE framework was employed to identify salient factors explicitly categorised according to the three dimensions of technology, organisation and environment. This offers opportunity to easily compare how BDA adoption is similar to, or different from other technologies adopted by organisations, as the TOE framework has widely been used to investigate many organisational technologies, for example, cloud computing (Nedev 2014), ERP (Oliveira \& Martins 2011) and so on. In addition, this study aimed to extend the TOE framework so as to understand the deployment gap in BDA adoption. To this end, the factors of complexity tolerance and paradigm shifts (Chen et al. 2015b) were also included in our research model.
The case study findings largely support the propositions derived from the literature. The adoption of BDA in the telecommunication organisation is shown as dependent on technological, organisational and environmental factors. The technological factors that drive adoption are relative advantage, compatibility, trialability and data quality, whilst complexity negatively affects the adoption process. The organisational factors positively influencing adoption are top management support, human resource expertise and businessIT alignment, whilst organisational size may have negative effects on the adoption process because of the greater organisational complexities in large organisations. In the environmental context, competitive pressure, IT fashion (hype) and vendor support are positive influences on adoption, whilst data privacy concerns have a negative effect on the adoption process. Regulatory requirements were shown as an important consideration in the BDA adoption process. Most of these factors have been identified as influencing adoption of other technologies in organisations (Oliveira \& Martins 2011); however, there are a few that are specific to the BDA context,

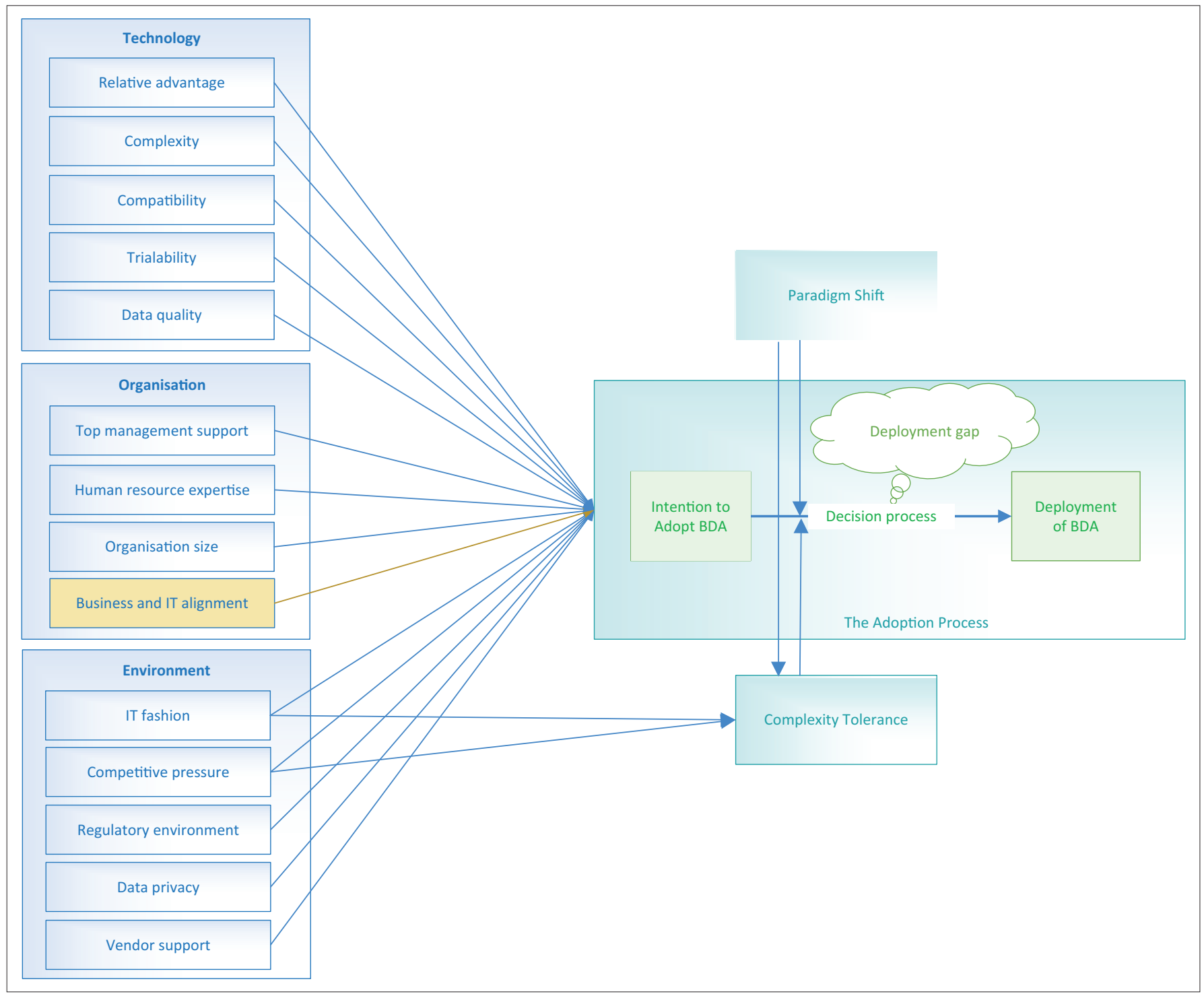

Source: Adapted from Tornatzky, L. \& Fleischer, M., 1990, The process of technology innovation, Lexington Books, Lexington, MA; and Chen, H.-M., Kazman, R. \& Matthes, F., 2015b, 'Demystifying big data adoption: Beyond IT fashion and relative advantage', DIGIT 2015 Proceedings, viewed n.d., from https://aisel.aisnet.org/digit2015/4/

FIGURE 1: Final combined technology-organisation-environment framework and Big Data Adoption model. 
for example, data quality in the technology domain and data privacy concerns in the environmental domain. It might be argued that these latter factors are just as relevant to the adoption of other data-oriented technologies such as BI or data warehousing, but with big data, they take on added significance given its characteristics of volume, velocity, variety, veracity, value, variability and visualisation (Mikalef et al. 2018). In addition to these TOE factors, there was also support for the moderating influence of complexity tolerance and paradigm shifts on the adoption process, thereby reducing the deployment gap (Chen et al. 2015b). Complexity tolerance was also shown as being influenced by competitive pressure, IT fashion (hype) and the degree of paradigm shift.

Figure 1 provides an overview of the final model. All these factors, classified according to the TOE framework, with extensions from the Big Data Adoption model of Chen et al. (2015b), provide a comprehensive explanation of BDA adoption in organisations.

\section{Conclusion}

The initial aim of this study was to identify and evaluate the factors influencing the adoption process of BDA. During the literature review, it was identified that difficulties in measuring the success of BDA suggested that there is no 'one size fits all' solution. The potential value will differ between the various sectors worldwide (Jokonya 2015). This study focused on the telecommunications sector as it is understood that the industry will benefit significantly from BDA and telecommunication executives are treating BDA as a strategic priority (Jony, Habib \& Mohammed 2015). Using a combined TOE framework and factors from the Big Data Adoption model (Chen et al. 2015b; Tornatzky \& Fleischer 1990), a list of testable propositions was developed and validated as illustrated in Figure 1. Empirical data were collected using a single case study in which nine participants were interviewed from a large telecommunication organisation. This study confirms that organisations that have a high tolerance for complexity are more likely to move rapidly from intention to adopt BDA to actual deployment and effectively reducing the deployment gap.

The study found that although BDA provides significant benefits over traditional BI systems, the majority of the participants agreed that it would not replace existing systems. The finding that BDA is part of a wider ecosystem suggests further research should be conducted to understand the role of BDA in this ecosystem. Quantitative studies can also be conducted to establish the strength of relationships between the identified TOE factors and adoption, as well as the moderating influence of complexity tolerance and paradigm shifts on the adoption process. Finally, given the increased rates of BDA adoption in organisations, research attention can now shift to understanding the success of such initiatives and the benefits accrued.

\section{Acknowledgements Competing interests}

The authors have declared that no competing interest exists.

\section{Authors' contributions}

R.S.W. conducted the overall study whilst registered as a student at the University of Cape Town. I.B. supervised the study and contributed to the writing of the article.

\section{Funding information}

This research received no specific grant from any funding agency in the public, commercial or not-for-profit sectors.

\section{Data availability statement}

Data sharing is not applicable to this article as no new data were created or analysed in this study.

\section{Disclaimer}

The views and opinions expressed in this article are those of the authors and do not necessarily reflect the official policy or position of any affiliated agency of the authors.

\section{References}

Abbasi, A., Sarker, S. \& Chiang, R.H., 2016, 'Big data research in information systems: Toward an inclusive research agenda', Journal of the Association for Information Systems 17(2), 1-31. https://doi.org/10.17705/1jais.00423

Ahmad, A., Ahmad, R. \& Hashim, K., 2016, 'Innovation traits for business intelligence successful deployment', Journal of Theoretical and Applied Information Technology 89(1), 96

Babbie, E.R., 2015, The practice of social research, Wadsworth, Belmont, CA

Braun, V. \& Clarke, V., 2006, 'Using thematic analysis in psychology', Qualitative ResearchinPsychology3(2),77-101.https://doi.org/10.1191/1478088706qp063oa

Chen, D., Preston, D. \& Swink, M., 2015a, 'How the use of big data analytics affects value creation in supply chain management', Journal of Management Information Systems 32(4), 4-39. https://doi.org/10.1080/07421222.2015.1138364

Chen, H.-M., Kazman, R. \& Matthes, F., 2015b, 'Demystifying big data adoption: Beyond IT fashion and relative advantage', DIGIT 2015 Proceedings, viewed n.d., from https://aisel.aisnet.org/digit2015/4/.

Chwelos, P., Benbasat, I. \& Dexter, A.S., 2001, 'Empirical test of an EDI adoption model', Information Systems Research 12(3), 304-321. https://doi.org/10.1287/ isre.12.3.304.9708

Czarnecki, C. \& Dietze, C., 2017, 'Understanding today's telecommunications industry', in Reference architecture for the telecommunications industry, pp. 17-54, Springer, Cham.

Fredriksson, C.N., 2015, 'Model of big data failure: Review of information system failure', Master's thesis in Information System Science, Turku School of Economics.

Hung, S.-Y., Huang, Y.-W., Lin, C.-C., Chen, K.-C. \& Tarn, M., 2016, 'Factors influencing business intelligence systems implementation', in PACIS 2016 Proceedings 297, AIS eLibrary, viewed 14 Oct 2019, from https://aisel.aisnet.org/pacis2016/297.

Hu, X., Yuan, M., Yaoy, J., Dengy, Y., Chenz, L., Yangz, Q. et al., 2015, 'Differential privacy in telco big data platform', Proceedings of the VLDB Endowment 8(12), 1692-1703. https://doi.org/10.14778/2824032.2824067

lederan, O.C., Curseu, P.L. \& Vermeulen, P., 2009, 'Effective decision-making: The role of cognitive complexity in strategic decisions', Studia Psychologica 51(4), 293.

Jokonya, O., 2015, 'Towards a conceptual framework for big data adoption in organizations', in Proceedings of the 2015 International Conference on Cloud Computing and Big Data (CCBD), IEEE Computer Society, Washington, DC November 04-06, 2015, pp. 153-160.

Jony, R.I., Habib, A. \& Mohammed, N., 2015, 'Big data use case domains for telecom operators', in 2015 IEEE International Conference on Smart City, IEEE, Chengdu, China, December 19-21, 2015, pp. 850-855.

Jooste, C., Van Biljon, J. \& Mentz, J., 2014, 'Usability evaluation for business intelligence applications: A user support perspective', South African Computer Journal 53(Special issue 1), 32-44.

Kappelman, L., McLean, E., Johnson, V. \& Gerhart, N., 2014, 'The 2014 SIM IT key issues and trends study', MIS Quarterly Executive 13(4), 237-263.

Klein, H.K. \& Meyers, M.D., 1999, 'A set of principles for conducting and evaluating interpretive field studies in information systems', MIS Quarterly 23(1), 67-93.

Lehrer, C., Wieneke, A., Vom Brocke, J., Jung, R. \& Seidel, S., 2018, 'How big data analytics enables service innovation: Materiality, affordance, and the individualization of service', Journal of Management Information Systems 35(2), 424-460. https://doi.org/10.1080/07421222.2018.1451953

Malaka, I. \& Brown, I., 2015, 'Challenges to the organisational adoption of big data analytics: A case study in the South African telecommunications industry', in Proceedings of the 2015 Annual Research Conference on South African Institute of Computer Scientists and Information Technologists, Article No. 27, Stellenbosch, South Africa, September 28-30, 2015. 
Mikalef, P., Pappas, I.O., Krogstie, J. \& Giannakos, M., 2018, 'Big data analytics capabilities: A systematic literature review and research agenda', Information
Systems and e-Business Management 16(3), 547-578. https://doi.org/10.1007/ Systems and e-Busines
s10257-017-0362-y

Mneney, J. \& Van Belle, J.-P., 2016, 'Big data capabilities and readiness of South African retail organisations', in Proceedings of the 2016 6th International Conference Cloud System and Big Data Engineering (Confluence), IEEE, Amity University Uttar Pradesh, Noida, India, January 14-15, 2016, pp. 279-286.

Nedev, S., 2014, 'Exploring the factors influencing the adoption of cloud computing and the challenges faced by the business', Enquiry-The ACES Journal of Undergraduate Research 5(1).

Oliveira, T. \& Martins, M., 2011, 'Literature review of information technology adoption models at firm level', Electronic Journal Information Systems Evaluation 14(1), 110-121.

Rogers, E., 2010, Diffusion of innovations, Simon and Schuster, New York, NY.

Salleh, K. \& Janczewski, L., 2016, 'Adoption of big data solutions: A study on its security determinants using sec-TOE framework', in CONF-IRM 2016 Proceedings. 66, AIS elibrary, viewed n.d., from http://aisel.aisnet.org/confirm2016/66.
Saunders, M., Lewis, P. \& Thornhill, A., 2009, Research methods for business students, 5 edn, Pearson Education Limited, England.

Sun, S., Cegielski, C.G., Jia, D.J. \& Hall, D.J., 2018, 'Understanding the factors affecting the organizational adoption of big data', Journal of Computer Information Systems $58(3), 193-203$.

Tornatzky, L. \& Fleischer, M., 1990, The process of technology innovation, Lexington Books, Lexington, MA.

Verma, D.C. \& Verma, P., 2014, Techniques for surviving the mobile data explosion, John Wiley \& Sons, Hoboken, NJ.

Wamba, F.S., Gunasekaran, A., Akter, S., Ren, S.J.-F., Dubey, R. \& Childe, S., 2017, 'Big data Research 70(January) 356-365. https://doi.org/10.1016/j.jbusres.2016.08 Business

Yin, R.K., 2013, 'Validity and generalization in future case study evaluations', Evaluation 19(3), 321-332.

Zhu, J., Zhuang, E., Fu, J., Baranowski, J., Ford, A. \& Shen, J., 2016, 'A framework-based approach to utility big data analytics', IEEE Transactions on Power Systems 31(3), 